\title{
Ibero-American initiative for dual disorders to improve public treatment programs
}

\author{
Luis Alfonzo-Bello, ${ }^{1}$ Néstor Szerman, ${ }^{2}$ Rodrigo Marín-Navarrete, ${ }^{3}$ Elisabet Arribas-lbar, ${ }^{2}$ Alejandro Pérez-Lopez, ${ }^{3}$ \\ Francisco Babín, ${ }^{4}$ María Elena Medina-Mora ${ }^{5}$
}

1 Departamento de Enfermedades No Transmisibles y Salud Mental, Organización Panamericana de la Salud, Washington, United States.

2 Sociedad Española de Patología Dual, Madrid, España.

${ }^{3}$ Unidad de Ensayos Clínicos en Adicciones y Salud Mental, Instituto Nacional de Psiquiatría Ramón de la Fuente Muñiz, Ciudad de México, México.

${ }^{4}$ Delegación del Gobierno para el Plan Nacional de Drogas de España, Madrid, España.

${ }^{5}$ Dirección General, Instituto Nacional de Psiquiatría Ramón de la Fuente Muñiz, Ciudad de México, México.

Correspondence:

Luis Alfonzo-Bello

Departamento de Enfermedades No Transmisibles y Salud Mental, Organización Panamericana de la Salud (OPS/OMS).

52523 rd St. NW, Washington D.C., United States.

Phone: +1 2029743539

Email: alfonzol@paho.org

Received first version: October 30 , 2017

Accepted: November 23, 2017

doi. 10.17711/SM.0185-3325.2017.032

\begin{abstract}
Introduction. Dual disorders (DD) are defined as the co-occurrence of substance use disorders with other psychiatric disorders across the lifespan. DD represent a diagnostic dimension with clinical peculiarities and specific healthcare needs, which raises the need to implement integrative treatment algorithms. However, worldwide, most programs address this condition through serial or parallel approaches. In Latin America, as in the rest of the world, there is no health care network that adequately addresses this problem. Objective. To describe the development of the initiative for the integral treatment of DD in Latin America. Method. The Organización Panamericana de la Salud (Pan American Health Organization), together with other collaborating organizations, implemented a three-stage plan for developing a regional initiative: 1. meeting of DD experts, 2. review of the literature on DD, and 3. identification of services for DD care in Latin America. Results. The creation of the Iniciativa Iberoamericana para la Patología Dual (Ibero-American Initiative for Dual Disorders) seeks to implement four lines of action to improve of public services: a) build a theoretical-conceptual consensus on DD, b) propose a treatment model, c) develop skills-based training, and d) create collaborative networks for research on DD. Discussion and conclusion. The following actions include the formation of working groups to create a regional collaborative network, discuss the role of participating organizations and establish guidelines for the implementation of the initiative.
\end{abstract}

Keywords: Dual disorders, substance use disorder, mental disorders, addictions, Ibero-American countries.

\section{RESUMEN}

Introducción. La patología dual (PD) se define como la coocurrencia de trastornos por uso de sustancias con otros trastornos psiquiátricos a lo largo del ciclo vital. La PD representa una dimensión diagnóstica con peculiaridades clínicas y necesidades asistenciales específicas, lo que implica la necesidad de implementar algoritmos de tratamiento integrativos. Sin embargo, la mayoría de los programas en el mundo ofrecen sólo modelos que atienden de forma serial o paralela esta condición. En Latinoamérica, como en el resto del mundo, no se cuenta con una red de atención sanitaria que aborde correctamente esta problemática. Objetivo. Presentar el desarrollo de la iniciativa para el abordaje integral de la PD en Latinoamérica. Método. La Organización Panamericana de la Salud, junto con otras organizaciones colaboradoras, implementó un plan de trabajo de tres etapas para generar una iniciativa regional: 1. reunión de expertos en PD, 2. revisión de la literatura sobre PD, y 3 . identificar los servicios para atender la PD en Latinoamérica. Resultados. Se generó una Iniciativa Iberoamericana para la Patología Dual. Ésta pretende implementar cuatro líneas de acción para mejorar los servicios públicos: a) generar un consenso teórico-conceptual sobre PD, b) proponer un modelo de tratamiento, c) desarrollar un entrenamiento basado en competencias, y d) crear redes de colaboración para la investigación en PD. Discusión y conclusión. Las siguientes acciones incluyen la conformación de grupos de trabajo para crear una red colaborativa regional, discutir el rol de las organizaciones participantes y establecer lineamientos para la implementación de la iniciativa.

Palabras clave: Patología dual, trastorno por uso de sustancias, trastornos metales, adicciones, países iberoamericanos. 


\section{INTRODUCTION}

Dual disorders (DDs) are defined as the co-occurrence or concomitance of substance use disorders (SUDs) with other psychiatric disorders (OPDs), clinical conditions that may develop sequentially or in parallel across the lifespan (Marín-Navarrete \& Szerman, 2015; Szerman et al., 2013). In the field of psychiatry, this phenomenon has become increasingly important and attracted growing interest from clinicians and researchers around the world due to the significant impact it has on public mental health.

Relative to individuals diagnosed with SUD without co-occurrence of OPD, those with DDs make more use of specialized services and general medicine, due to their diagnostic complexity. This group shows poor treatment adherence, higher relapse and rehospitalization rates, a greater risk of contracting sexually transmitted infections, higher suicide ideation and behavior, school and work dropout rates, more legal problems in general, and greater biopsychosocial deterioration, leading to a substantial increase in public healthcare costs (Marín-Navarrete et al., 2016a; Marín-Navarrete, Magis-Rodríguez, \& Strathdee, 2017; Substance Abuse and Mental Health Services Administration \& Center for Substance Abuse Treatment, 2005; Torrens, Mestre-Pintó, \& Domingo-Salvany, 2015).

Historically, it has been thought that among individuals with SUD, only a minority shows co-occurrence with OPD. However, scientific evidence has shown that the cases of individuals with DDs are the rule rather than the exception (Marín-Navarrete \& Szerman, 2015; Szerman et al., 2013). Studies performed on the general population estimate a lifetime prevalence of DDs in between $20 \%$ and $50 \%$ of the cases (Kessler et al., 1996), while studies on the clinical population report lifetime prevalences ranging from 50\% to $75 \%$ (Marín-Navarrete et al., 2013), and of $40 \%$ to $65 \%$ in the past 30 days (Substance Abuse and Mental Health Services Administration \& Center for Substance Abuse Treatment, 2005; Arias et al., 2013; Marín-Navarrete et al., 2016a).

DDs represent a diagnostic dimension with clinical particularities and specific healthcare needs, which demand the implementation of integrative intervention algorithms incorporating the treatment of the co-occurring psychiatric symptomatology (Teesson, Degenhardt, Proudfoot, Hall, \& Lynskey, 2005). However, most programs and healthcare networks offer models that address this condition through serial or parallel approaches (Vega et al., 2015).

A possible explanation for this is the division within the public healthcare system, which separates treatment networks for SUDs and OPDs in many countries. This increases healthcare costs, and reduces the effectiveness of treatment, which in turn leads to the convoluted navigation of the patient across the healthcare system, and promotes the revolving door phenomenon characterized by poor ad- herence, treatment dropout, relapses, and re-hospitalization (Priester et al., 2016; Substance Abuse and Mental Health Services Administration \& Center for Substance Abuse Treatment, 2005; Vega et al., 2015). A US report estimated that $44 \%$ of individuals with DDs receive treatment, but that only $7 \%$ of them receive treatment for both conditions, and that $55 \%$ do not receive any type of treatment (Center for Behavioral Health Statistics and Quality, 2015). Other reasons that explain this situation are barriers to treatment access such as: a) lack of treatment programs attending DDs with integrated approach; b) limited number of qualified staff with skills for diagnosis and treatment; and c) reduced offer of programs with integrative strategies for ethnic, racial diversities, and gender needs (Blumenthal, Gokhale, Campbell, \& Weissman, 2001; Foster, LeFauve, Kresky-Wolff, \& Rickards, 2010; Priester et al., 2016).

Global public addiction programs have traditionally maintained a substance-focused approach (for alcohol, tobacco, marijuana, cocaine, etc.), which is very different from what DDs care requires, since it involves an approach centered on individuals with SUD and their multiple co-occurring psychopathological expressions. A DD-centered paradigm would involve a more responsive approach to the patient's needs and a better prognosis in the rehabilitation process (Dansky, Roitzsch, Brady, \& Saladin, 1997; Drake, Mercer-McFadden, Mueser, McHugo, \& Bond, 1998; Priester et al., 2016; Vega et al., 2015).

In Ibero-America, as in the rest of the world, there is no healthcare network that correctly addresses the problem of DDs. Since the 80s, diverse groups of researchers and clinicians have performed multiple efforts to study and treat the phenomenon of DDs, as it is shown by the published scientific evidence mostly undertaken by the US, Canada, and European countries.

In response to this problem, the Pan American Health Organization (PAHO/WHO), in a strategic partnership with the Government Delegation for the Spanish National Drug Plan (DGPNSD, for its acronym in Spanish), have decided to promote an initiative that strengthens the public healthcare and contributes to the improvement of DDs treatment programs. This initiative will have the support and scientific collaboration of experts from the Spanish Society of Dual Disorders (SEPD, for its acronym in Spanish), an organization with more than 20 years of experience in the dissemination, research and teaching of DDs, and the Instituto Nacional de Psiquiatría Ramón de la Fuente Muñiz (INPRFM, for its acronym in Spanish), a 40-years experienced institution for the research on addictions and mental health, which will serve as a PAHO/ WHO collaborating center.

The purpose of this article is to describe the development of the initiative for an integral approach to DDs in Ibero-American countries. 


\section{METHOD}

PAHO/WHO and DGPNSD, through SEPD and INPRFM, developed a multistage work plan to establish a clearly-defined strategy for the implementation of the initiative, through the formation of a leading team composed of a DDs expert from each institution.

\section{Stage 1: Meeting of DD Experts}

The leading implementation team convened a task force comprising addiction and mental health experts from the United States, Spain, Mexico, Chile, Uruguay, Argentina, Peru, Colombia, Cuba, Panama, Venezuela, Costa Rica, and Brazil, with the aim of: a) engendering a regional debate on conceptual aspects regarding the public health response to DDs; b) drawing up a proposal for an integral approach to DDs; and c) outlining an action plan to be developed in the period 2016-2018.

The task force was convened under the project: Integral Approach to the Co-occurrence of Disorders due to the Use of Psychoactive Substances and Other Mental and Behavioral Disorders in Latin American Countries. The meeting was held on December $8^{\text {th }}$ and $9^{\text {th }}, 2015$ in Washington, DC.

An intensive working agenda for two days was set up. During day one, expert meetings were held; in these, researchers from SEPD and INPRFM were responsible for presenting the scientific basis of the theoretical and conceptual aspects of DDs such as: epidemiology, treatment services, and human resource training. At the end of each presentation, the attendees discussed the information until they reached points of agreement. On day two, discussion groups were held for exchanging experiences regarding the approaches to DDs in Ibero-American countries, on the basis of the topics reviewed the previous day. Each discussion group was coordinated by a moderator who was responsible for introducing the topic and supervising the discussion among experts. The duration of each working group was approximately 90 minutes.

Although the number of experts in the meeting was limited to ten, over 100 specialists from all the guest countries participated through video conference. Web participants also engaged in the discussions with real-time online voice, text questions, and comments.

The discussion groups identified the following needs:

- Need 1: To establish the work schedule, goals, and outputs of the initiative, as well as a follow-up strategy through: telephone calls, video conferences, and e-mails.

- Need 2: To prepare a systematic review of published scientific literature on DDs in Latin American countries to determine the importance of the topic in the region.

- Need 3: To undertake a regional analysis of supply and demand in DDs care services.

\section{Stage 2: Review of literature on DDs}

In keeping with the needs previously identified, the purpose of this stage was to explore the current scientific evidence on DDs in Latin American countries, through a systematized search of original articles (Marín-Navarrete et al., 2016b). The timeframe for the search was January 2000 to December 2016. Two general search algorithms were used, the first of which included the terms: dual diagnosis or dual disorder or dual pathology or co-occurring or comorbid* and Latin America (or name of the Latin American country), while the second included the terms: substance *use or addicti* and depress* or anxiety or attention deficit or adhd or antisocial or schizophr* or bipolar and Latin America (or name of the Latin American country).

The databases used for the search were PubMed, SciELO, Web of Knowledge, Scopus, and APA PsycNET. Each algorithm included the following names of Latin American countries: Argentina, Brazil, Bolivia, Chile, Colombia, Costa Rica, Cuba, Guatemala, Honduras, Jamaica, Mexico, Nicaragua, Panama, Paraguay, Puerto Rico, Uruguay, and Venezuela. The criterion for selecting articles for review were that the title should include terms associated with "Dual Disorders", "SUD", "OPD", or indicators of psychiatric disorders.

A total of 72 articles met the selection criteria for review (Table 1) and most of the published articles (93.5\%) included a cross-sectional design (Marín-Navarrete et al., 2016b).

The countries with the highest number of publications on the subject were Brazil ( $n=36)$, Mexico $(n=16)$, Colombia $(n=6)$, and Chile $(n=5)$. The review also showed that the most commonly used instruments for the diagnosis of SUD or OPD were the International Composite Diagnostic Interview (Robins et al., 1988), the Mini International Neuropsychiatric Interview (Sheehan et al., 1997), and the Structured Clinical Interview of the DSM-IV for Axis I (Lobbestael, Leurgans, \& Arntz, 2011), while the instruments used for

Table 1

Studies on co-occurring disorders in Latin America

\begin{tabular}{lccccc}
\hline Country & $\begin{array}{c}\text { Cases } \\
\text { and control }\end{array}$ & Cohorts & $\begin{array}{c}\text { Clinical } \\
\text { trials }\end{array}$ & $\begin{array}{c}\text { Cross-sec- } \\
\text { tional studies }\end{array}$ & Total \\
\hline Brazil & 4 & 2 & 1 & 29 & 36 \\
Chile & & - & - & 5 & 5 \\
Colombia & 1 & - & - & 5 & 6 \\
Costa Rica & & - & - & 2 & 2 \\
Guatemala & - & - & - & 2 & 2 \\
Jamaica & - & - & - & 1 & 1 \\
Mexico & 2 & - & - & 14 & 16 \\
Nicaragua & - & - & - & 1 & 1 \\
Panama & - & - & - & 1 & 1 \\
Paraguay & - & - & - & 1 & 1 \\
Uruguay & - & - & - & 1 & 1 \\
\hline
\end{tabular}


detections were the Hospital Anxiety and Depression Scale (Zigmond \& Snaith, 1983); the Hamilton Depression Scale (Bagby, Ryder, Schuller, \& Marshall, 2004), Depression Scales (Huang, Hsieh, Wu, \& Lu, 2017), and Beck's Anxiety Index (Magán, Sanz, \& García-Vera, 2008).

Despite efforts made in Latin America, the results showed that the number of publications in scientific journals on the subject is limited (this is particularly critical when comparing to other developed countries such as the US, Canada, and those in Europe). Furthermore, the heterogeneity of the methodology, diagnostic interviews or screening scales, and study population (household vs. clinical sites), makes it difficult to compare the reported findings. This in turn prevents obtaining the information on the prevalence of DDs, the characteristics of those seeking care in treatment centers, available healthcare models, or the specialized and non-specialized human resources at the healthcare systems for serving the population with this condition.

This scenario led the task force to develop a strategy to reach out researchers and decision makers who could provide information on issues related to service provision for DDs care in their countries, as described in Stage 3.

\section{Stage 3: DDs Care Services}

In keeping with Need 3 of Stage 1, a task force of experts from the countries included in the initiative $(n=8)$ was consulted to determine the demand for health services for the care of individuals with DDs and to assess the response of existing services in public health networks.

To this end, a self-administered form with four domains was developed: 1 . information on the prevalence of psychiatric disorders in treatment services in each country, 2. legal and political framework, 3. current status of public services, and 4. training for professionals. Task force members used national registers, technical reports, and/or official publications corresponding to their country to fill in the form. Data were collected between April and July of 2016.

For the analysis of the information, the data presented by the experts from each country were reviewed and discussed at a technical meeting held in the city of Cartagena de Indias, Colombia, from September $5^{\text {th }}$ to $8^{\text {th }}, 2016$, yielding the following results:

Regarding the prevalence of co-occurrence between SUDs and OPDs at treatment services, only two experts reported that their country had national records, although these data are unpublished. The other participants said that their countries did not have records with information on this issue. However, they reported personal and consensual views that prevalence in mental health treatment centers ranges from $25 \%$ to $65 \%$, whereas in addiction treatment centers, it ranges from $45 \%$ to $75 \%$. They also estimated that the most prevalent disorders in patients seeking treatment for SUD were: antisocial personality, major depres- sion, generalized anxiety, psychotic disorders, and attention deficit/hyperactivity disorder.

As for the legal and political framework, the eight experts reported that their countries have a mental health law or regulation. Six of the respondents reported a law or regulation on SUDs and none cited a law or regulation of DDs. On this last point, only the expert from Uruguay reported that a policy for providing care for those with DDs is being developed in his country.

Regarding the current status of treatment services, all eight experts declared that in their countries there is one public network for mental health and another for the care of SUD. In all the countries, care services for SUD and OPD are divided, and the responsibility of the Ministries of Health, and in most countries, the connection between these networks is either limited or non-existent. Likewise, most of the services are provided by government institutions, followed by non-profits together with a modest yet costly supply of private medical services.

The experts also agreed that the most common access barriers to the services in both networks are: long waiting times, unawareness of available treatment services, lack of gender-sensitive programs, high care costs, and an insufficient supply of treatment services.

Regarding the results of human resource training, only the expert from Mexico reported that there are specific training courses in DDs designed for psychiatrists in his country.

\section{RESULTS}

It was found that: a) the available evidence on DDs in Latin America is limited and that the ability of health systems to provide care for those with DDs is restricted; b) it is necessary to expand the supply of specialized services that attend both conditions in an integral way; c) there is an urgent need for DDs training programs for the professionals and non-professionals comprising the addiction treatment and mental health care network; d) it is essential to promote lines of research aimed at providing Latin American scientific evidence on DDs, and lastly, e) participants confirmed the need for a consensus on the theoretical and conceptual aspects of DDs with the aim of standardizing experts' knowledge on the issue and reducing possible theoretical discrepancies.

The Ibero-American Initiative for Dual Disorders was developed on the basis of these findings. This initiative seeks to implement four lines of action that will serve as the basis for the improvement of public services for addiction treatment and mental health care (Figure 1).

\section{Line 1: Theoretical-conceptual consensus on DD}

The aim is to integrate available scientific information, as well as the knowledge of researchers and clinical experts on 
- The leading implementation team convened a task force comprising addictions and mental health experts.

- The task force met in December 2015 in Washington DC, to a) debate the public health response to addressing DDs, b) define a proposal for treating DDs and c) draw up an action plan to be developed during in the two-year period 2016 to 2017.

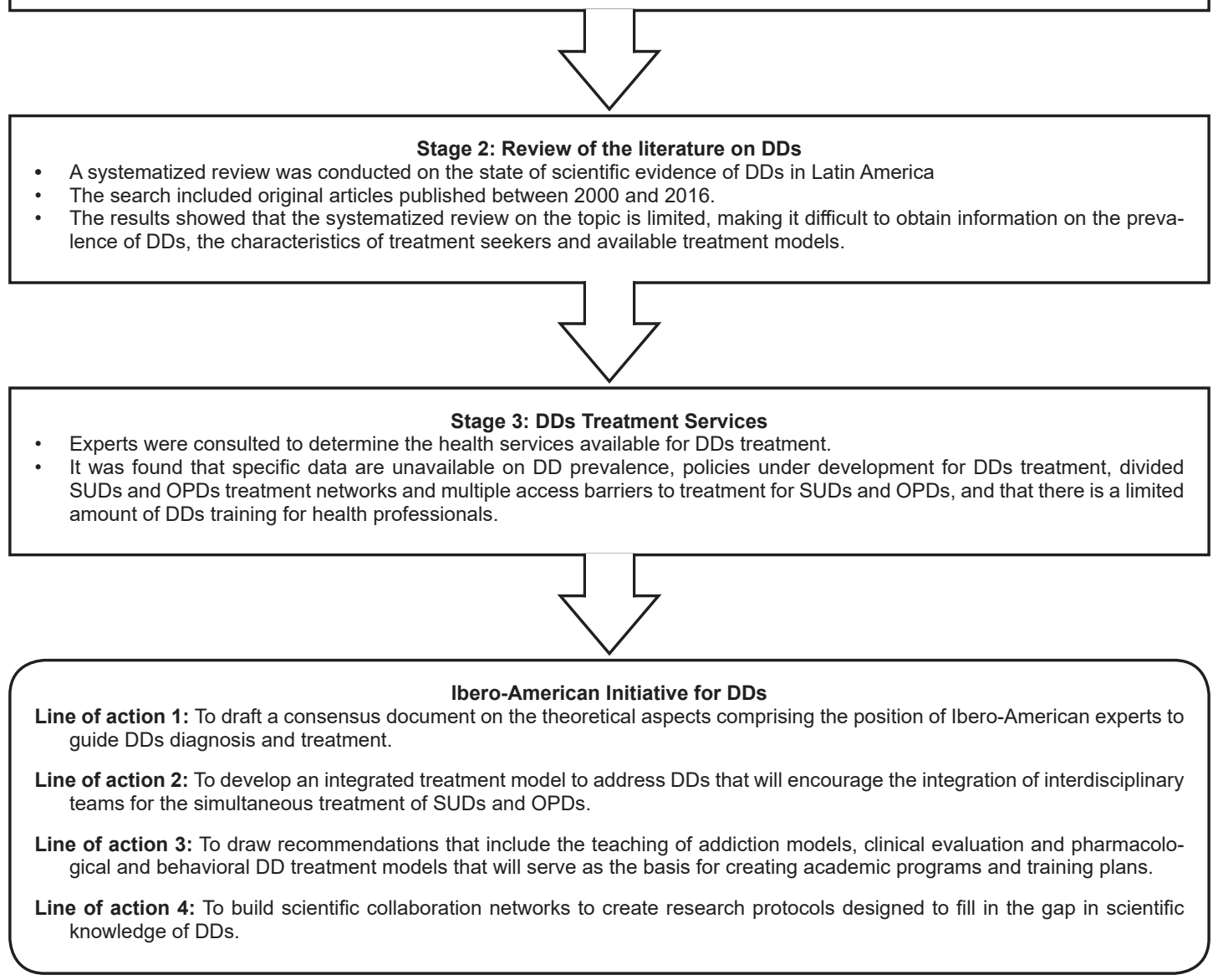

Figure 1. Development of Ibero-American Initiative for Dual Disorders.

Note: $\mathrm{DDs}=$ Dual Disorders; OPDs = Other Psychiatric Disordes; SUD = Substance Use Disorders.

the many theoretical aspects associated with the co-occurrence of SUDs and OPDs.

The aspects to be addressed in the consensus focus on the prevalence of DDs, procedures used for the detection and evaluation of patients with this condition, the treatment algorithms utilized, the training received by mental health professionals, and the research activities conducted by mental health professionals in Latin America.

The goals of the consensus on DDs include the following: a) to put together a paper on theoretical aspects based on scientific evidence that reflects the positioning of a group of experts in Latin America; b) to generate consensus through a research protocol that will guide the actions for diagnosis and treatment of DDs; and c) to submit recommendations that will impact on professional practice, public policies, professional preparation and integrated treatments in Latin American countries.

\section{Line 2: Development of a comprehensive treatment proposal for DD}

This line seeks the strengthening and formation of interdisciplinary teams that offer integrated treatment for the co-occurrence of SUDs and OPDs. This treatment approach is expected to be able to address the multiple symptomatic expressions of those with DDs in a single clinical setting. It is also expected to increase the likelihood of success of this treatment modality.

The proposal will combine behavioral and pharmacological interventions with scientific evidence of their effectiveness for DDs treatment. Models should include the treatment of acute psychiatric symptomatology, good practices for addressing co-occurring disorders, the implementation of pharmacologically assisted detoxification algorithms, interventions for opiate dependence care, programs for the 
care of patients with sexual risk behavior and intravenous substance use in order to reduce the risk of blood-borne infections, and include gender-sensitive approaches.

\section{Line 3: Training for specialized and non-specialized professionals}

The aim is to develop a proposal for DDs training, which includes the teaching of addiction models, clinical evaluation, and pharmacological and behavioral treatment models. This proposal will serve as the basis for the creation of academic programs for the training of human resources in the area of health, which will cover the care and treatment needs of people with DD.

This proposal would seek to promote permanent training programs for professionals already working at addiction or mental health treatment centers. It would attempt to develop specific clinical skills among professionals, which will reduce treatment barriers, associated with the low availability of specialized services, health personnel training, clinical identification of DDs, and delivery of the most adequate treatment.

With regard to non-specialized personnel offering their services through civil organizations, the aim would be to increase conceptual theoretical knowledge and basic skills in DDs, and to develop derivation and referral algorithms promoting collaborative work between public and private institutions.

\section{Line 4: Research on DDs in Ibero-America}

In order to fill the gap in scientific knowledge on aspects associated with DDs, as identified in Stage 2, an Ibero-American strategy would be developed with the aim of creating collaboration networks between institutions to: a) standardize measuring instruments that would make it possible to generate clinical evidence for comparing data among countries; b) standardize integral treatment models for DD care; c) implement randomized clinical trials to determine the efficacy of pharmacological and behavioral treatments in order to meet the cultural and healthcare systems needs of the region; d) describe the public and private services available for DDs care; e) detect training needs for clinical staff in the mental health and addictions system; and f) assess the degree of willingness to change and motivation to adopt treatment programs to address DDs.

\section{DISCUSSION AND CONCLUSION}

The purpose of this article was to describe the development of an initiative to provide an integral approach to DDs in Ibero-American countries. As a result of a multi-stage implementation and the integration of a task force, the propos- al for this initiative consists of four lines of action designed to improve public services for addictions and mental health care: a) to develop a theoretical consensus on DDs; b) to propose an integrated treatment model for co-occurrence of SUDs and OPDs; c) to develop skills-based training in DDs; and d) to create collaborative networks for research on DDs in Latin American countries.

Despite the planning and goals proposed by the initiative, implementing the lines of action will encounter specific social, cultural, and political obstacles in each collaborating country, as well as variations in the knowledge, attitudes, and beliefs of the professionals and organizations comprising the mental health care and addictions treatment networks.

Accordingly, the science of implementation (Fixsen, Naoom, Blase, Friedman, \& Wallace, 2005) will be useful for designing strategies to increase the acceptability and adoption of the products of the initiative, such as the implementation of research protocols, DDs detection and treatment models, and training for health professionals. For example, in the case of the implementation and maintenance of DDs treatment models, it will be necessary to establish clinical supervision systems with continuous support, comprising clinical expert, to ensure the sustainability and maintenance of the strategies implemented. This is because there is evidence that training in innovations does not suffice to put them into practice. Specialists are required to supervise the practice of clinicians and support them in decision-making. The strategic actions of the task force are also expected to include the formation of specialized working groups to identify key actors in civil society, academic centers, government agencies and funding sources to form the regional collaboration network, and to discuss the role each organization should play in implementing the initiative and establish guidelines for the development of the proposed lines of action.

Lastly, the Ibero-American Initiative for Dual Disorders is an innovative proposal to create multidisciplinary collaborative networks comprising experts from various countries in the region, generate scientific evidence on various aspects of DD, establish integrated treatment programs for addressing DD, integrate mental health and addiction service networks, reduce barriers to treatment access, and develop training and education programs for health professionals.

\section{Funding}

None.

\section{Conflicts of interests}

The authors declare they have no conflicts of interest. The results described in this manuscript do not represent the official positions of the institutions represented.

\section{Acknowledgements}

The authors are particularly grateful to the experts from all the countries that have participated in the task force for their valuable 
contributions and time in developing this initiative. Also, special thanks are due also to Agencia Española de Cooperación Internacional para el Desarrollo (AECID) to support the meetings of the task force.

\section{REFERENCES}

Arias, F., Szerman, N., Vega, P., Mesias, B., Basurte, I., Morant, C., ... \& Babín, F. (2013). Estudio Madrid sobre prevalencia y características de los pacientes con patología dual en tratamiento en las redes de salud mental y de atención al drogodependiente. Adicciones, 25(1), 118-127.

Bagby, R. M., Ryder, A. G., Schuller, D. R., \& Marshall, M. B. (2004). The Hamilton Depression Rating Scale: Has the gold standard become a lead weight? The American Journal of Psychiatry, 161(12), 2163-2177. doi: 10.1176/appi. ajp.161.12.2163

Blumenthal, D., Gokhale, M., Campbell, E. G., \& Weissman, J. S. (2001). Preparedness for clinical practice: reports of graduating residents at academic health centers. JAMA: The Journal of the American Medical Association, 286(9), 10271034. doi: 10.1001/jama.286.9.1027

Center for Behavioral Health Statistics and Quality (2015). Behavioral health trends in the United States: Results from the 2014 National Survey on Drug Use and Health. Retrieved from: http://www.samhsa.gov/data/

Dansky, B. S., Roitzsch, J. C., Brady, K. T., \& Saladin, M. E. (1997). Posttraumatic stress disorder and substance abuse: Use of research in a clinical setting. Journal of Traumatic Stress, 10(1), 141-148. doi: 10.1002/jts.2490100114

Drake, R. E., Mercer-McFadden, C., Mueser, K. T., McHugo, G. J., \& Bond, G. R. (1998). Review of integrated mental health and substance abuse treatment for patients with dual disorders. Schizophrenia Bulletin, 24(4), 589-608. doi: 10.1093/oxfordjournals.schbul.a033351

Fixsen, D., Naoom, S., Blase, K., Friedman, R., \& Wallace, F. (2005). Implementation Research: A synthesis of the Literature. Tampa: University of South Florida, Louis de la Parte Florida Mental Health Institute.

Foster, S., LeFauve, C., Kresky-Wolff, M., \& Rickards, L. D. (2010). Services and supports for individuals with co-occurring disorders and long-term homelessness. Journal of Behavioral Health Services and Research, 37(2), 239-251. doi: 10.1007/s11414-009-9190-2

Huang, S. L., Hsieh, C. L., Wu, R. M., \& Lu, W. S. (2017). Test-retest reliability and minimal detectable change of the Beck Depression Inventory and the Taiwan Geriatric Depression Scale in patients with Parkinson's disease. Plos One, 12(9), e0184823. doi: 10.1371/journal.pone.0184823

Kessler, R. C., Nelson, C. B., McGonagle, K. A., Edlund, M. J., Frank, R. G., \& Leaf, P. J. (1996). The epidemiology of co-occurring addictive and mental disorders: Implications for prevention and service utilization. American Journal of Orthopsychiatry, 66(1), 17-31. doi: 10.1037/h0080151

Lobbestael, J., Leurgans, M., \& Arntz, A. (2011). Inter-rater reliability of the Structured Clinical Interview for DSM-IV Axis I Disorders (SCID I) and Axis II Disorders (SCID II). Clinical Psychology \& Psychotherapy, 18(1), 75-79. doi: $10.1002 /$ cpp.693

Magán, I., Sanz, J., \& García-Vera, M. P. (2008). Psychometric properties of a Spanish version of the Beck Anxiety Inventory (BAI) in general population. The Spanish Journal of Psychology, 11(2), 626-40.
Marín-Navarrete, R., Benjet, C., Borges, G., Eliosa-Hernández, A., Nanni-Alvarado, R., Ayala-Ledesma, M., ... \& Medina-Mora, M. E. (2013). Comorbilidad de los trastornos por consumo de sustancias con otros trastornos psiquiátricos en Centros Residenciales de Ayuda-Mutua para la Atención de las Adicciones. Salud Mental, 36(6), 471-479.

Marín-Navarrete, R., \& Szerman, N. (2015). Repensando el concepto de adicciones: pasos hacia la patología dual. Salud Mental, 38(6), 395-396. doi: 10.17711/ SM.0185-3325.2015.60

Marín-Navarrete, R., Medina-Mora, M. E., Horigian, V. E., Salloum, I. M., Villalobos-Gallegos, L., \& Fernández-Mondragón, J. (2016a). Co-Occurring Disorders: A Challenge for Mexican Community-Based Residential Care Facilities for Substance Use. Journal of Dual Diagnosis, 12(3-4), 261-270. doi: 10.1080/15504263.2016.1220207

Marín-Navarrete, R., Szerman, N., Toledo-Fernández, A., Villalobos-Gallegos, L., Pérez-López, A., Brzezinski, A., \& Lezama-Bautista, A. (2016b). Estado de la Evidencia sobre Patología Dual en Latinoamérica. Poster presented at the $18^{\circ}$ Congreso Internacional en Adicciones de Centros de Integración Juvenil, Acapulco, México.

Marín-Navarrete, R., Magis-Rodríguez, C., \& Strathdee, S. A. (2017). Sexually transmitted infections and substance use disorders: evidence and challenges in Mexico. Salud Mental, 40(1), 1-4. doi: 10.17711/SM.0185-3325.2017.001

Priester, M. A., Browne, T., Iachini, A., Clone, S., DeHart, D., \& Seay, K. D. (2016). Treatment Access Barriers and Disparities Among Individuals with Co-Occurring Mental Health and Substance Use Disorders: An Integrative Literature Review. Journal of Substance Abuse Treatment, 61, 47-59. doi: 10.1016/j. jsat.2015.09.006

Robins, L. N., Wing, J., Wittchen, H. U., Helzer, J. E., Babor, T. F., Burke, J., ... \& Towle, L. H. (1988). The Composite International Diagnostic Interview. Archives of General Psychiatry, 45(12), 1069-1077. doi: 10.1001/archpsyc. 1988.01800360017003

Substance Abuse and Mental Health Services Administration \& Center for Substance Abuse Treatment (2005). Substance Abuse Treatment for Persons With Co-Occurring Disorders: A Treatment Improvement Protocol (TIP) Series 42. Rockville: Substance Abuse and Mental Health Services Administration.

Sheehan, D. V., Lecrubier, Y., Harnett, K., Janavs, J., Weiller, E., Keskiner, A., ... \& Dunbar, G. (1997). The validity of the Mini International Neuropsychiatric Interview (MINI) according to the SCID-P and its reliability. European Psychiatry, 12(5), 232-241. doi: 10.1016/S0924-9338(97)83297-X

Szerman, N., Martinez-Raga, J., Peris, L., Roncero, C., Basurte, I., Vega, P., ... \& Casas, M. (2013). Rethinking Dual Disorders/Pathology. Addictive Disorders \& Their Treatment, 12(1), 1-10. doi: 10.1097/ADT.0b013e31826e7b6a

Teesson, M., Degenhardt, L., Proudfoot, H., Hall, W., \& Lynskey, M. (2005). How common is comorbidity and why does it occur? Australian Psychologist, 40(2), 81-87. doi: 10.1080/00050060500094605

Torrens, M., Mestre-Pintó, J. I., \& Domingo-Salvany, A. (2015). Comorbidity of substance use and mental disorders in Europe. Lisbon: European Monitoring Centre for Drugs and Drug Addiction.

Vega, P., Szerman, N., Roncero, C., Grau-López, L., Mesías, B., Barral, C., ... \& Casas, M. (2015). Recursos y Necesidades Asistenciales en Patología Dual. Madrid: Sociedad Española de Patología Dual.

Zigmond, A. S., \& Snaith, R. P. (1983). The hospital anxiety and depression scale. Acta Psychiatrica Scandinavica, 67(6), 361-70. 